\title{
Linguistic and Cultural Worldview of Modern Bilingual Chinese American Writers
}

\author{
Svetlana Korovina ${ }^{1}$, Anna Pushkina ${ }^{2}$, Liudmila Krivoshlykova ${ }^{3}$, Anna Ilina ${ }^{4}$ \\ 1, 2, 3, 4 Faculty of Philology, Peoples' Friendship University of Russia, (RUDN University), \\ Moscow, Russia.
}

\begin{abstract}
:
The article deals with Chinese inclusions in the novels by modern Chinese American writers E. Tang and M.H. Kingston. In the process of the study different types of bilingualism are taken into consideration. Being bilingual representatives of the second-generation immigrants both E. Tang and M.H. Kingston can evaluate the level of linguistic and cultural assimilation of the Chinese in the multinational environment. The research is focused on the ways linguistic and cultural worldview of bilingual authors is reflected in their works. To reach the goal of the research the continuous sampling method is used to collect the data. Though in most cases the authors explain or translate inclusions, we find it important to track the origin of the inclusions under study. The analysis has shown that the majority of Chinese inclusions illustrate such basic cultural values as family circle, forms of address, cuisine and etc. Inclusions in the texts prove that root culture and newly acquired one peacefully coexist in Chinese community in the USA. The results indicate that inclusions employed by the authors in the novels reveal their personal emotional attitude to the characters and prove that their bilingualism and biculturalism help to bridge the gap between different cultures and nations.
\end{abstract}

Keywords: Bilingualism, inclusions, Chinglish, linguistic worldview, cultural identity

\section{INTRODUCTION}

The phenomenon of Asian-American ethnic literature as a significant component along with the mainstream of American literature attracts many researchers not only in North America but all over the globe. Recently a number of scientific papers investigating this problem from literary, cultural or historical points of view have been published in Russia. As the number of bilinguals is critically increasing more and more linguists and educators are involved in the bilingualism issue. For example, international Symposium on Bilingualism is one of the largest event devoted to bilingualism and multilingualism of the modern community. It was first held at the University of New Castle upon Tyne in 1997 and since then has become one of the most popular among experts in the field of linguistic diversity.

However, in our opinion, linguistic methods of literary work creation whose authors are representatives of the first generation of Asian Americans are studied insufficiently. We would like to fill this gap and examined the peculiarities of bilingualism in the novels by Amy Tan and Maxine Hong Kingston, ones of the brilliant and most original writers of modern times.

(C) AesthetixMS 2020. This Open Access article is published under a Creative Commons Attribution Non-Commercial 4.0 International License (http://creativecommons.org/licenses/by-nc/4.0/), which permits non-commercial re-use, distribution, and reproduction in any medium, provided the original work is properly cited. For citation use the DOI. For commercial re-use, please contact editor@rupkatha.com. 
First of all, let's look at the borrowed words from the Chinese language in the abovementioned novel. These linguistic borrowings not only enrich the vocabulary of the language filling lexical gaps but also help people of diverse nationalities to understand better the culture of the countries from which these foreign borrowings originate. It is safe to say that the history of the English language is the history of borrowings.

According to the Oxford English Dictionary, borrowed words from different languages make up about $70 \%$ of the English language vocabulary. However, there are not more than a thousand Chinese borrowings in English (Zhu 2011, p. 102). Originally, a large number of Chinese words became a part of the English language during the reign of Han and Tang dynasties and it continued its entry with the development of trade relations between the two countries. Chinese borrowings gradually assimilated in the vocabulary of Western merchants who also used Chinese as a language of trade.

Such words like tea and silk are bright examples of this assimilation process. According to the Oxford English Dictionary, the word silk (丝绸 [sīchóu]) dating back to 888 AD, came into the English language along The Great Silk Road through Latin and Greek. This fact states that Chinese silk production, which had already reached a high level by $550 \mathrm{BC}$, influenced the West.

Despite the fact that the generally accepted pronunciation of the word tea - is "chá" (茶), in Minnan dialect it sounds like "te". The Dutch merchants pronounced it like "tay" which consequently came into English under the well-known tea.

At present Chinglish, a variety of colloquial English influenced by the Chinese language, is rapidly spreading in the English-speaking world. The fact that word "Chinglish" is one of the Top Words of 2005 proves this statement (TopWords 2010).

\section{PROBLEM STATEMENT}

In modern American literature Chinglish is often used in works devoted either to the lives of Chinese in America, or penetration of Asian culture in (to) American. The novels by M. H. Kingston "Tripmaster monkey: his fate book" (1989) and A. Tan ("The Joy Luck Club" (1989), "The Bonesetter's daughter" (2001), "Saving fish from drowning" (2006)) are full of Chinese inclusions and borrowings.

These lexical units add Chinese authentic flavour to the novel and the reader finds himself directly involved in the plotline thanks to them. Foreign inclusions "accumulate social, historical, intellectual, emotional and evaluative information of both general human nature and specific national character", that finally "builds up nationally conditioned cultural component of semantic structure" inherent not only to a word but to the literary work on the whole" (Belchikov 1988, p. $31)$.

In a text foreign inclusion unlike borrowings remain their original form of the language they belong to. In the analyzed works these elements play different roles: they are used to refer to culturally specific phenomenon or realia which do not have English equivalent, to provide the character with authentic features, and sometimes to attach satirical shade of meaning to the speech.

The text full of foreign inclusions usually tells about the life of peoples, whose culture and language are unknown to the reader. Many inclusions get fully integrated into the recipient language and they gradually turn into borrowings. 


\section{RESEARCH QUESTIONS}

1. How is the authors' bilingualism presented on the lexical level?

2. How does bilingualism shape linguistic and cultural worldview of the authors?

\section{LITERATURE REVIEW}

The phenomenon of bilingualism has become the norm of modern society as a result of intense communicative relations of ethnic groups. According to G.M. Vishnevskaya (1997) it is bilingualism that is one of the most vivid manifestations of intercultural communication (p.5).

Before starting the study of the elements of bilingualism in the novels by Maxine Hong Kingston and Amy Tan, it is necessary to determine what the "bilingualism" phenomenon is. Here are various points of view.

The concept of "bilingualism" was first introduced in the $20^{\text {th }}$ century. For example, in 1938 V.A. Aurorin, defined it as equally fluent communication in two languages. In other words, bilingualism begins when the degree of knowledge of a second language is almost the same as the degree of knowledge of the first language (Aurorin 1972, p. 51).

It is important to highlight that starting from the first works on bilingualism, this phenomenon was considered as a complex, systematic, particularly personal phenomenon, which includes a certain linguistic structure, the ability to use the acquired system of signs in a communicative situation (communicative aspect), which includes wider general cultural representations and world views (sociocultural aspect).

G.T. Tavadov (2011) claims that bilingualism is simultaneous command of two or more languages (p. 43-45). Bilingualism means coexistence and functioning of two languages. In his book "Language System and Speech Activity", L.V. Shcherba (1974) defined bilingualism as ability of certain population groups to communicate in two languages" (p.72).

American linguist, one of the founders of sociolinguistics and outstanding linguists of the $2 \mathrm{O}^{\text {th }}$ century Uriel Weinreich gives a slightly different definition of bilingualism. In his well-known book "Languages in Contact: Findings and Problems" (1979) the author describes bilingualism as practice of alternative usage of two languages. He highlights the role of political, social and cultural environment in linguistic situation in a certain community (Weinreich 1979).

Mariam-Webster Dictionary defines bilingualism as the ability to speak two languages, as the frequent use (as by a community) of two languages and as the political or institutional recognition of two languages (Bilingualism).

Taking into consideration all the definitions, we can conclude that in modern linguistics there are many interpretations of the term "bilingualism", which reflect the different approaches of experts. Despite the different approaches, bilingualism takes place when an individual is able to effectively communicate in both languages. When studying bilingualism, scientists use various approaches: sociological, pedagogical, linguistic, psychological, culturological and literary, depending on the purpose of studying this phenomenon, since the problem of bilingualism is multidimensional. The most important role for the study of bilingualism is assigned to linguists and sociologists, since they deal with the functioning of language in society: sociologists study problems related to the behavior of a bilingual person or a group of people; linguists consider this 
phenomenon in connection with the text and from the point of view of the processes of interference, which will be discussed later.

According to some scientists, bilingualism is not a phenomenon but a process of language acquisition with its own criteria and classification, which are interconnected. In the table below, we'll give the examples of bilingualism received classification.

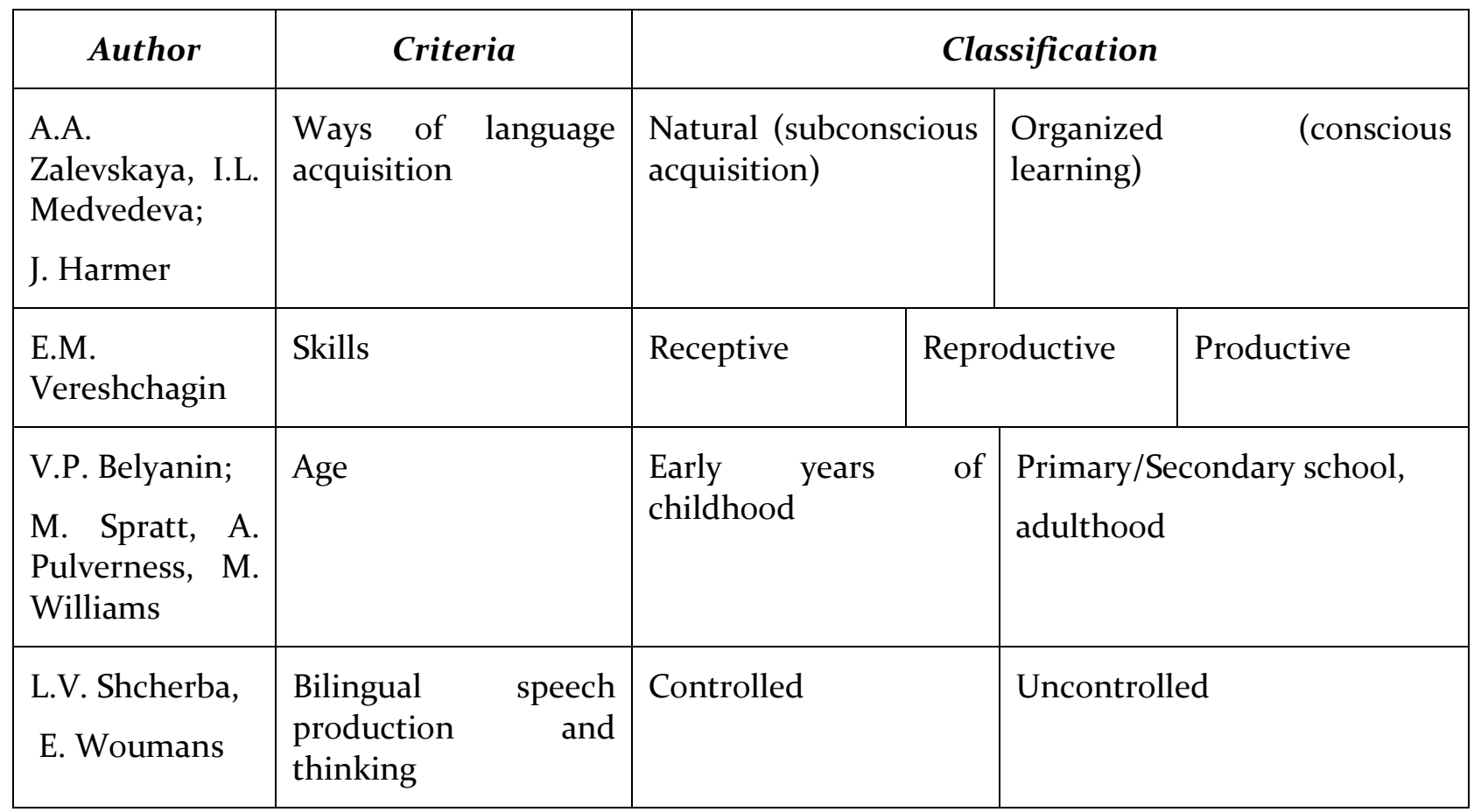

The table shows two types of bilingualism in terms of language acquisition: natural and organized (Zalevskaya \& Medvedeva 2002, p. 56).

- The first type is characterized by the natural learning environment, with an individual acquiring a language naturally, subconsciously, spontaneously. Thus, an individual is exposed to the language through TV, Internet resources, spontaneous conversation owing to strong motivation to interact with people in their surroundings. The rules of language are acquired in a "predictable order", utterances are made "from subconscious knowledge"; "speakers of the languages using them for real communication" (Krashen 2009, p. 1).

- The second type is about the process of acquiring a language that becomes the focus of learning in an organized environment in a classroom. It is taught and studied in a conscious and controlled way, with the language structure taken into account and proper educational tools applied (Harmer 2010, p. 51-53).

Ye.M. Vereshchagin (1969), a Russian linguist, emphasizes three types of bilingualism in terms of particular skills:

- receptive bilingualism involves receptive skills that imply a good understanding of what a certain audio, video or written text is about;

- reproductive bilingualism require skills which allow a person to cite or state on paper or orally what has been heard or read about; 
- productive bilingualism suggests skills to not only understand or cite information but also make clear, informative utterances both in written form and orally. Moreover, utterances should generate the language communicative function, and the same utterances can have a different communicative function in a different situation. Otherwise, communication cannot be effective, thus, this type of bilingualism cannot be referred to as the productive one (p. 27).

Another key concept specialists highlight when discussing a foreign language acquisition is the age issue. It includes early years of childhood and primary/secondary school or adulthood (V.P. Belyanin (2003); M. Spratt, A. Pulverness, M. Williams (2011)):

- The "early" bilingualism is shaped in the bilingual environment, bilingual culture since the early childhood in immigrant families or mixed marriages where children are born into and brought up commonly bilingually.

- The "late" bilingualism occurs at an older age when the first language basic cognitive skills are already formed.

In terms of speech production and thinking criteria some researchers consider the phenomenon of bilingualism to be controlled and uncontrolled (L.V. Shcherba (1974), E. Woumans (2015)):

- Under the controlled bilingualism people choose to use a "home language" communicating with their families and a "public language" when networking or socializing (Harmer 2013, p.132). That makes a bilingual belong to two different communities. E. Woumans (2015) comes to the conclusion that the language functions in an independent way. A bilingual's languages co-exist and are selected to use according to certain circumstances (p. 159-16o).

- Under the uncontrolled bilingualism people tend to use both languages while interacting with either their families or colleagues and friends. With that, they spontaneously switch from one language to the other without giving thought to which language they use in this or that situation. Consequently, the language systems appear to be interconnected during a communicative act (Shcherba 1974, p. 71-73).

However, despite the given classification most bilinguals are inclined to feel free when choosing a language to communicate, what lexis to use and how often. Besides, bilinguals' communicative acts are coloured in a sociocultural way, and it is not the linguistic component that matters but the speakers' background, their cultural specificity and identity.

Language and speech of a contemporary person is the result of the continuous historic development. Language is the most essential manifestation of culture of the human society. A person's identity with national culture is revealed on all levels of linguistic personality. These are the levels of national character and mentality, communication and cognition, emotion and motivation, body language and gestures. Thus, culture penetrates all levels of linguistic personality. Language is a system of landmarks in the world of objects. Thanks to ethnic culture the person creates his own world view and world image.

It is the interaction of various ethnic cultures that stimulates the emergence of such phenomenon as bilingualism. In the process of second non-native language usage the bilingual tries to reach its standard.

Interference is a key process in studying bilingualism, linguistic and ethnic assimilations. Interference is often understood as a process and result of language systems interaction, one of 
which is domineering, generating the effect of influence in the secondary acquired linguistic system (Vishnevskaya 1997, p.3). In other words, interference is influence of one language on the other. The native language usually influences a second (foreign) one, but on the advanced level of acquisition it may be visa versa.

Moreover, cultural and linguistic environment results in social and cultural interference, when a person perceives realia, norms, phenomena of different culture through their own experience of world perception.

The notions "integration" and "assimilation" are directly connected with ethnic groups interaction. According to A.I. Kirillova (2013), integration occurs in a unified way in terms of system of social relations, agreement, unity, common self-conscience and identity formation. Assimilation means absorption of the small ethnic group by the big one, and consequently, change of the way of life, language and culture in the minority ethnic group (p. 53).

This part of the article is devoted to ethnic and ethno-linguistic assimilation.

Bilingualism as a result of ethnic and ethno-linguistic assimilation is a common phenomenon in multinational communities, where national minority, besides their vernacular tongue, uses the language of the dominant nation, which is the national language. Bilingualism is common for the countries with big immigrant settlements. One of the countries like these is the USA where immigrants arrive from India, Mexico, the Philippines and China. The Chinese American community is the largest overseas Chinese community outside Asia. It is also the third largest community in the Chinese diaspora, behind the Chinese communities in Thailand and Malaysia. The 2016 Community Survey of the US Census estimates a population of Chinese Americans of one or more races to be 5,081,682 (U.S. Census Bureau 2016). The Chinese American community comprises the largest ethnic group of Asian Americans, comprising 25.9\% of the Asian American population as of 2010. Americans of Chinese descent, including those with partial Chinese ancestry constitute $1.5 \%$ of the total U.S. population as of 2017 . According to the 2010 census, the Chinese American population numbered approximately 3.8 million (U.S. Census Bureau 2010).

There are many reasons for Chinese migration to the USA. First of all, it is connected with the development of Chinese trade in the Pacific. Also, it's the development of the progressive capitalist relations in the US and poor economic and social situation in China, as a result, exodus from the country for better living (Biriukov 1983, p.27). Chinese were a cheap labour force for the US. They lived in Chinatowns, where they created their own authentic structure of the community. The wish of immigrants to keep their national identity, traditions, religious and family customs stimulated Chinatowns' growth. In the 90-s of the XX century the trend to preserve Chinese traditions was as vital/relevant as ever.

Modern trends of transformation and destruction of former family bonds in China along with the influence of American way of life on huaqiao /huáqiáo (overseas Chinese; Chinese citizens residing abroad) families led to the breach of family ties with recent immigrants and generally most Chinese of American origin. Young people especially those who were born in the USA are more and more dissatisfied with their parents' urge to retain their Chinese identity, starting with obligatory Chinese learning and using it within the family to strict juniors' obedience to seniors. This discrepancy in views and especially different attitudes of parents and children to moral values create unhealthy psychological atmosphere in American-Chinese families.

Touching upon the ethnic assimilation, Shehong Chen in his book "Being Chinese: Becoming Chinese American" (2002) in the 90-s held several interviews to study modern Chinese identity in American environment. Her study showed different attitude of American-born Chinese to their 
roots. They were proud of their Chinese heritage, they followed Chinese rituals and traditions. Although the respondents felt hesitant and worried when they were asked about their connections with China, the vast majority, all of them hoped "to see a strong China" (p.7).

Ethno-linguistic assimilation is a process of native tongue loss by an ethnic group both outside and inside ethnic group communication (Tavadov 2011, p. 43). Ethno-linguistic assimilation takes place in multinational cosmopolitan countries mainly in big cities. It is characteristic of young generation in the first place. One of the factors that boosts this process is mixed marriages. Linguistic assimilation is an important step in ethnic assimilation in general. It follows cultural and general assimilation and together with the loss of ethnic identity completes the process. Linguistic assimilation is a complete transference to another language, it refers to ethno-linguistic processes of evolutional character. Both processes undergo through social adaptation of an individual, his adjustment to new social, cultural, linguistic, confessional environment.

Issues induced by tense human and linguistic relationships within two ethnic groups related to identity of the Chinese in the USA are raised in the novels by Emi Tang, American writer of Chinese origin.

Arguably, immigrants of the first generation could hardly speak English, and representatives of later Huaqiao /huáqiáo generations refused to speak Chinese. According to some researchers English has become the main language of communication in Chinese families. Children from Chinese families learn English in state schools on regular basis that's why, if parents are busy at work and have time to communicate with them only in the morning and evening, the children lose speaking skills in Chinese that they were taught in early childhood in the family and in Chinese schools.

\section{CHINESE INCLUSIONS IN THE NOVELS UNDER STUDY}

In the article we present the analysis of ways cultural world view is reflected in the language. Our research is based on the examples of M.H. Kingston and A. Tan's works ("Tripmaster monkey: his fake book" (1989), "The Joy Luck Club" (1989), "The Bonesetter's daughter" (2001), "Saving fish from drowning" (2006)) written in English. We focused on such aspects of Chinese culture as philosophy, music, food, clothes, morals, kinship terms.

The study has shown that inclusions make up a considerable part of Chinese elements in the analyzed novels. The main role of these inclusions is to emphasize the national peculiarities inherent to Chinese community in America.

The meanings of some of them can only be surmised as there is neither equivalent, nor explanatory translation in the text. For example:

"Do you still have dock-yee knees, honey boy? You have got to tap-dance for your Aunt Lilah again.”

$$
\text { (Kingston 1989, p.184) }
$$

We can say for sure that the word dock-yee in the following example is to a certain extent connected with dancing movements, as tap-dance is described in the abstract.

Some inclusions are repeated in the text that is why it is the context that defines their meanings. For example, the word gwai: 
Only, after a couple of cities, Doctor Ng changed it to Doctor Woo and the Chinese Flora Dora Girls so that the low fawn gwai would have no problem reading the flyers.

(Ibid, p.13)

"Grow rat beard. And go out with bok gwai noi."

(Ibid, p.183)

Both examples refer to a white man. In the first example, we can assume that it is the American, resident of the towns where Doctor Woo performed, who could have difficulty reading the advertising flyers, because the Chinese language seems exotic and unlike European languages. In the second example, the inclusion is used in the speech of Wittman's mother. She is a representative of a more conservative generation and is disappointed that her son has grown long hair and a beard, which was trendy in those times, and brings home a white girl whom he calls his friend. By the way, to name a foreigner another word waiguoren (外国人[wàiguórén]) can be used:

"He is American," warned my mother, as if I had been too blind to notice. "A waiguoren."

$$
\text { (Tan 1989, p. 124) }
$$

In the next sentence it is easy to understand that ba means dad (爸 [bà] - father) as Wittman greets his father.

"Wittman. Just my son", said Pop by way of greeting.

"Hi, Ba. Hello, Uncles."

(Kingston 1989, p.197)

In "Bonesetter's Daughter" by A. Tan the same address to a father is used without translation in the situation with the parrot which cries imitating the girl's voice:

"Baba! Baba! Don't beat me! Please don't beat me!"

(Tan 2001, p. 291)

There is another example of inclusion from a novel by Kingston the meaning of which is clear from the context:

"My ah-pok-mun", he said, opening the door wide to his roomland, switching on the overhead light, which also switched on the desk lamp."

(Kingston 1989, p.28)

Wittman opens the door to his room showing it to his girlfriend. The word ad-pok-mun can be interpreted as "room" or "dwelling".

In the following example it is evident that hong mu Hóngmù (红木) means red wood:

"My table was from my family and was of very fragrant red wood, not that you call rosewood, but hong $\mathbf{m u}$, which is so fine where is no English world for it."

(Tan 1989, p. 11) 
Thus, we can conclude that, though, there are inclusions in a novel whose meanings are unclear to a reader it is possible to understand them from the context.

It is worth noting that in «Saving fish from drowning» by Amy Tan most of the Chinese inclusions are directly translated or explained in English. From A. Tan's prospective, it should facilitate an English reader's perception of the situations, personalities, and relations among main characters described by the author. To add expressiveness to the novel the author uses Chinese inclusions in her own speech and that of her characters. Let us illustrate it with some examples. The stepmother of Bibi Chen, the main character, interprets her Chinese father's words regarding Bibi's name:

"And your father clapped his hands and said there was an expression that meant exactly that: bibi jie shi - can be found everywhere."

(Tan 2006, p. 27)

The name Bibi and a part of a fixed expression 比比皆是 [bǐ bǐ jiē shì] «a great number, everywhere is just the same» are homonyms. Without any comments the meaning of the whole passage will be misinterpreted or mistranslated by English speaking readers who do not speak Chinese.

Chinese first names and family names consist of two or three hieroglyphs, each of them has its own symbolic meaning. The Chinese believe that the way a name sounds determines the destiny of a person. That is why it is so important for parents to choose a child's first name which sounds harmonious with the family name.

She was named Bao Tian - «Sweet Bud» - which was not quite suitable.

(Tan 2006, p. 20)

Here Bibi Chen talks about her mother-in-law's name. A beautiful name opposed to bed temper of the woman aims to highlight conflict between the girl and her mother-in-law, who in her turn comments on Bifang's name.

"Bifang your mother named you, though heaven knows I tried to persuade her to choose something else. "Good reputation jade" sounds like an advertisement poster, in my opinion, what pleases the ear of those who don't know better."

$$
\text { (Tan 2006, p. 26) }
$$

In her novels symbolic names of the characters function as stylistic devices, they help the author to portray their personalities, make them more realistic and vivid.

Both translation and comment of a Chinese inclusion:

Her mother still called her "Wawa", a Chinese name for "baby."

Wawa, the sound of a crying doll. She hated being called hat.

(Tan 2006, p. 102)

We stick to the point that the author combines translation and expressive comparison on purpose, he makes the reader experience all the feelings of the teen-ager. 

inclusions.

In some cases the author of the novel under review uses the verb "to mean" to explain

"Moong cha cha. Both of them, father and son, moong cha cha." <...> "Moong cha cha" means "spacy", spaced out and having to grope like a blindman.

(Kingston 1989, p.180)

To describe his relations with Tanya, Whitman uses a Chinese word intentionally to conceal from her the fact that he is calling/calls her just a friend:

"Hey, Taňa," he called over to her table. "Meet my mother, Ruby Ah Sing. Ma, meet my pahng yow, Tan-ah." "Pahng yow" means "friend"; maybe Taňa would think it meant "wife."

(Tan 2006, p. 180)

In the novel «Bonesetter's daughter» Amy Tan uses the same method:

"Bao Bomu taught me how to write," LuLing said one evening. "She taught me how to think. When you write, she said, you must gather the free-flowing of your heart." To demonstrate, Luling wrote the character for "heart." "See? Each stroke has its own rhythm, its balance, its proper place. Bao Bomu said everything in life should be the same way."

“Who's Bao Bomu again?” Ruth asked.

"She took care of me when I was a girl. She loved me very much, just like a mother. Bao, well, this means 'precious,' and together with bomu, this means 'Precious Auntie.' "

(Tan 2001, p. 52-53)

It should be noted that in Chinese the word bomu (伯母 [bómǔ]) is a form of address to an aunt, the word bao (宝) means “precious" or "treasure”. According to the text, Bao Bomu (宝 [băo] Precious + 伯母[bómǔ]) [Precious Auntie] is a very important person in Loolin’s life.

In Kingston's novel «Tripmaster Monkey: His Fake Book» the majority of Chinese inclusions are translated by the author in the text of the novel. Such inclusions are both in the characters' and the author's words. Most of them are lexical units and are to be translated for thorough understanding of Chinese culture. Sometimes the translation is essential to better understand some episodes, relations between the characters and the author's point of view.

Inclusions in the characters' speech highlight their ethnicity and are followed by the author's translation:

As he stepped out - her own fault, she hadn't locked the door she called him some of the many Chinese words for "crazy" "Saw! Deen! Moong cha cha! Ngow! Kang!"

(Kingston 1989, p. 43)

"I'm not your grandmother, boy. Jook tsing!" Bamboo head.

(Kingston 1989, p. 251) 
11 | Linguistic and Cultural Worldview of Modern Bilingual Chinese American Writers

"Ho sick, la. Ho sick", she said. "Good eating. Good eats."

(Kingston 1989, p. 5)

\section{BASIC COMPONENTS OF THE CHINESE CULTURE}

The main goal of our research was to highlight the ways basic components of the Chinese culture are represented. All the examples were divided into the following groups.

\section{Family circle}

The whole family in Chinese is called Dajya [dàjiā (大家)].

"Dajya"- All the family - she said happily.

(Tan 1989, p. 67)

Mother, father are conveyed as mama, baba [māma (妈妈), bàba (爸爸)]:

"The third word in the next line", explained Baba...

(Tan 1989, p. 68)

Mama was telling my aunt and the old ladies how to mix various herbs and insects to produce a balm...

(Tan 1989, p. 69)

Baba was in a new brown-colored gown ... Mama had on a jacket and skirt with colors that were reverse of mine: black silk with yellow bands.

$$
\text { (Tan 1989, p. 71) }
$$

The following example presents the polite words for wife:

She had called my mother Taitai, the simple honorable title of wife, as if my mother were the first wife, the only wife [taitai ( 太太)].

(Tan 1989, p. 251)

Nuyer [Nuyer nǚér (女儿)] means daughter:

"Nuyer is here. Your daughter is back."

(Tan 1989, p. 37)

For the youngest brother in the family there is a special word in Chinese, i.e. Syaudi [xiăodì (小弟)]:

"He is Syaudi, your littlest brother", my mother whispered.

(Tan 1989, p. 259)

Jyejye [jiějie (姐姐)] and meimei [mèimei (妹妹)] stand for elder sister and younger sister respectively: 
"Jyejye, Jyejye. Sister, Sister. We are here," I saw myself saying in my poor version of Chinese.

(Tan 1989, p. 310)

My sisters look at me, proudly. "Meimei jandale," says one sister proudly to the other. "Little Sister has grown up."

(Tan 1989, p. 331)

Jandale [zhăngdà (长大)] means to grow up (zhăng (长 grow) dà (大 big)) + le [le (了)] (suffix) which is used to express the completion of an action or a change of a state.

For aunt they use Aiyi [āyí (阿姨)] and for elderly woman in the family Popo [pópo (婆婆)], which is a highly positive connotation. It should be noted that in some dialects Popo means grandmother or mother's mother.

Aiyi! Aiyi! - Auntie! Auntie! - he says softly.

(Tan 1989, p. 314)

Now Aiyi beams and points to a Polaroid picture of my father.

(Tan 1989, $p$. 315)

So I knew Popo wanted me to forget my mother on purpose, and this is how I came to remember nothing of her.

(Tan 1989, p. 33)

This was my uncle and auntie's family house, where I lived with Popo and my little brother.

(Tan 1989, p. 33)

Nanny or maid is considered a family member and is called Amah [āmā (阿妈)]:

My scalp was burning with the pain of Amah's attention.

(Tan 1989, p. 67)

Amah finally noticed me and gave me a mooncake ...

(Tan 1989, p. 69)

\section{Chinese culture}

Owing to intercultural communication and its long-lasting effects, especially after China had started its reforms and carried out the policy of interaction with outer world and permits to immigrate from China, the notions as feng shui (风水 [fēngshuǐ]), kung fu (功夫 [gōngfu]), wu shu (武术[wǔshù]) have made their thorough way into English.

\section{- Philosophy}

The Chinese culture also enriched English with such notions as Yin Yang (阴阳[yīnyáng ]), which define one of the main ideas of the Chinese natural philosophy originating from "The book of changes". Yin means the dark, passive, female principle of the universe while Yang is male, light, active, and penetrating. That is why Whitman fretted about a Chinese General's name as Yin: 
The name of that movie was The Bitter Tea of General Yin. They named him that to castrate us. General Yin instead of General Yang, get it? Again the china man made into woman.

(Kingston 1989, p. 322)

\section{- Clothes}

The following sentence contains the word cheongsam (in Mandarin Chinese - 长衫 [chángshān]) which literally means "a long shirt". It is a traditional Chinese woman's silk dress with a mandarin collar and skirt-slits on two sides (in Mandarin dialect it is called 旗袍[qípáo]). This word came from the Cantonese cheung sam:

Auntie An-mei were dressed up in cheongsam, in funny

Chinese dresses with stiff stand-up collars and blooming

branches of embroidered silk sewn over their breasts. These

clothes were too fancy for real Chinese people, I thought, and

too strange for American parties.

(Tan 1989, p. 16)

Then - here they come - "orientals", all in a group. A guy and three chicks, one in cheongsahm.

(Kingston 1989, p. 58)

\section{- Musical instruments}

Amy Tan also uses another borrowing, it is a name of a well-known traditional Chinese musical instrument erhu (二胡 [èrhú], one of the most important Chinese instruments, with a history of over 4,ooo years. Though it has only two strings, it can convey a wide range of emotions. The erhu is called the "Chinese violin" (Shen Yun Performing Arts):

By the time we reached John F. Kennedy Drive, the band was playing a squeaky version of «Amazing Grace» on the twostringed erhu...

(Tan 1989, p. 42)

\section{- Martial arts}

M. Hong Kingston's novel has a great variety of borrowings from Chinese. For example, borrowings connected with martial arts:

Heading toward him from the other end came a Chinese dude from China, hands clasped behind, bow-legged, loose-seated, out on a stroll - that walk they do in kung fu movies when they are full of contentment on a sunny day.

(Kingston 1989, p. 5)

Making slow kung fu tai chi moves, Wittman pushed hands and feet circularly.

(Ibid, p. 145) 
The traditional Chinese martial art of kung fu (in the mandarin dialect 功夫 [gōngfu]) as well as the health-improving gymnastics of tai chi (太极拳[tàijíquán]) became well-received in the West in 1970-s along with the martial arts-based films with Bruce Li starring. Nowadays, kung fu and tai chi trainings in the USA are as popular as yoga trainings.

The epoch of Chinese martial arts spreading in the West includes the word chi borrowed from the mandarin dialect of Chinese (气 [qi]). It means "air", "steam", "spirit". However, in the traditional Chinese culture it is a vital force, a spiritual power circulating within a human body:

\section{The champ had been gesturing and some chi got loose/}

(Ibid, p. 278)

\section{- Cuisine}

Among the borrowings from Chinese there is a number of words from the famous Chinese cuisine, some of the popular dishes and their names are very ancient. Tofu is one of the best-known food products ((豆腐 [dòufũ] «cheese made of soya»), it was invented in China in II century B.C.

In her novel Amy Tan mentions the dish called ma-po tofu, which means tofu with green peas, minced meat, hot garlic and soya sauce.

The third surprise was a spicy bean curd. "I've eaten ma-po tofu all my life," Marlena said. But this one tastes strange. I'm not quite sure I like it."

\section{(Tan 2006, p. 104)}

Tofu is quite a peculiar cheese made of soya milk, it became a very popular Chinese food product in North America. The word tofu was borrowed from Japanese, but is of Chinese origin. (in Chinese it sounds [doufu]: which means 豆[soya] + 腐[to rot]). The Americans learned the word tofu in the middle of the 2o-th century, because of the growing interest in eastern cultures and the increasing popularity of vegetarianism.

Or you find some actual name in the Chinatown phone book, and when that king of tofu hears the white Government voice on the phone, he'll say he doesn't speak English.

\section{(Kingston 1989, p. 249)}

Famous Chinese tea, pressed in the form of a small cake, «Pu erh tuo cha» (普洱沱茶[pǔ'ěr tuóchál) is mentioned in the following example from «Saving fish from drowning» by Amy Tan:

We were sampling different Pu erh tuo cha-which is, by the way, the only tea that improves over time; anything else, after six months, you may as well use for kitty-cat litter».

\section{(Tan 2006, p. 10)}

Borrowed from the Cantonese chop suey is mentioned in the next sentence. Chop suey, which is in the Mandarin 砸碎 [zásuì], meaning “mixed pieces/bits of smth." is a Chinese-American dish created by Chinese cooks who worked on railways on the American western coast at the Golden Rush times. Nowadays this dish is very popular among other Chinese dishes in the USA. Along with chop suey the word mah-jong (麻将[májiàng], which means one of the Chinese games, is used here: 
Is "mah-jong" a white word, then, like "chop suey", a white food?

(Kingston 1989, p. 183)

Another popular morning or early afternoon meal in a family or friends circle is mentioned.

"We're going to meet at a dim sum parlor, and he'll drive me home."

(Kingston 1989, p. 268)

Dim Sum means "a little bit of heart" in Chinese and small dishes in Cantonese. There is a great variety of meat, fish, vegetarian dim sum which is usually cooked by steaming or frying served in small portions with three or four pieces (Chinatown New York City Fact Sheet).

\section{CONCLUSION}

The study has shown that on the lexical level the authors' bilingualism is presented by such concepts as family, philosophy, music, food, clothes, etc. It proves that national traditions, norms and morals are characteristic of Chinese ethnic group in the USA.

The authors depict reality through the prism of individual cultural worldview. The inclusions in the novels are taken by readers for granted and they do not function as so-called exoticisms. As it was mentioned above, though there are inclusions in a novel the meanings of which are unclear to a reader they are easily understood from the context. Moreover, the authors provide explanations or translations of inclusions in the very text. Thus, it shapes the reader's vision of the national character, or emphasizes the ethnical singularity of the characters' world view.

Though assimilation means change of cultural identity and ethnic self-conscience, it does not mean that identity vanishes immediately. Root identity and newly-acquired one may coexist. The main peculiarity of the authors' worldview is combination of national and distinctive individual components so the reader perceives the atmosphere of the literal text as it is viewed by the author. Employing certain linguistic means the author encodes his or her personal emotional attitude towards the events and characters described, thus making the reader experience the same feelings and emotions.

\section{ACKNOWLEDGMENT}

The publication has been prepared with the support of the "RUDN University Program 5-10o".

\section{REFERENCES}

Aurorin, V.A. (1972). Dvuyazychiye i shkola [Bilingualism and school]. In Problemy dvuyazychiya i mnogoyazychiya [Problems of bilingualism and multilingualism] (pp. 49-62). Moscow: Nauka.

Belchikov, Yu.A. (1988). O kul'turnom konnotativnom komponente leksiki [Cultural connotative component of vocabulary] In Yazyk: sistema i funktsionirovaniye [Language: system and operation] (pp. 30-35). Moscow: Nauka.

Belyanin, V.P. (2003). Психолингвистика. - Moscow: Moscow psikhologo-sotsial'nyy Institute.

Bilingualism. In Mariam-Webster Dictionary. Retrieved from https://www.merriamwebster.com/dictionary/bilingualism. 
Biriukov, V.I. (1983). Kitaytsy v SSHA i amerikano-kitayskiye otnosheniya na sovremennom etape [The Chinese in the United States and the US-China relations at the present stage]. Moscow: Nauka.

Chen, Shehong (2002). Being Chinese: Becoming Chinese American. Champaign: University of Illinois Press, Chinatown New York City Fact Sheet. Retrieved 2 March, 2019 from www.explorechinatown.com.

Harmer, J. (2010). How to Teach English. Harlow: Pearson Education Limited.

Harmer, J. (2013). The practice of English language teaching. fourth edition. Harlow: Pearson Educational Limited.

Kingston, M.H. (1989). Tripmaster Monkey: His Fake Book. NY: Alfred Knopf.

Kirillova, A.I. (2013). Vzaimodeystviye kul'tur: integratsiya, assimilyatsiya i vospitatel'naya rol' obshchestva. [The Interaction of Cultures: Integration, Assimilation and the Educational Role of Society]. Sotsiodinamika. No.1: 53-152. DOI: 10.7256/2306-0158.2013.1.319

Krashen, S. (1985). The input hypothesis: Issues and implications. - London: Longman. https: // www.uio.no/studier/emner/hf/iln/LING4140/ho8/The\%2oInput\%2oHypothesis.pdf

Krashen, S.D. (2009). Principles and Practice in Second Language Acquisition. Pergamon Press.

Spratt, M., Pulverness, A., Williams, M. (2011). The TKT Course. Modules 1, 2 and 3. 2nd ed. Cambridge: Cambridge University Press.

Shen Yun Performing Arts. Retrieved from http://www.shenyunperformingarts.org/ learn/article/read/item/94I3V_FwFbM/chinese-music-instruments-erhu-violin.html date of access: $10 / 01 / 2018$

Shcherba, L.V. (1974) Language System and Speech Activity. Leningrad: Nauka.

Tan, A. (2001). The Bonesetter's Daughter. NY: Putnam's sons.

Tan, A. (1989). The Joy Luck Club. NY: Ivy Books.

Tan, A. (2006). Saving Fish from Drowning. NY: Ballantine books.

Tavadov, G.T. (2011). Etnologiya. Sovremennyy slovar'-spravochnik [Ethnology. Contemporary Dictionary]. Moscow: Dialog Cultur.

Top Words (2010). The Global Language Monitor. Retrieved from http://s4484o.gridserver.com/?page_id=4

U.S. Census Bureau (2016). American FactFinder: Results. Retrieved from http://factfinder.census.gov.

U.S. Census Bureau (2010). Race Reporting for the Asian Population by Selected Categories: 2010. Retrieved from https://factfinder.census.gov/bkmk/table/1.o/en/.../QTP8

Vereshchagin, Ye.M. (1969). Psikhologicheskaya i metodicheskaya kharakteristika dvuyazychiya (Bilingvizma) [Psychological and Methodological Characteristics of Bilingualism]. Moscow: Moscow State University.

Vishnevskaya, G.M. (1997). Bilingvizm i yego aspekty [Bilingualism and its aspects]. Ivanovo: Ivanovsky

State University.

Weinreich, U. (1979). Languages in Contact: Findings and Problems. The Hague: Mouton.

Woumans, E. (2015). Effects of Bilingualism on Cognition. Retrieved from http://users.ugent.be/ wduyck/articles/Woumans2015.pdf

Zalevskaya, A.A. \& Medvedeva, I.L. (2002). Psikholingvisticheskiye problemy uchebnogo dvuyazychiya [Psycholinguistic problems of educational bilingualism]. Tver': Tver' State University.

Zhu, Kui (2011). On Chinese-English Language Contact through Loanwords. - English Language and Literature Studies, Vol.1, No.2, 100-105. 